\title{
Alterations in apolipoprotein B-48 in the postprandial state in NIDDM
}

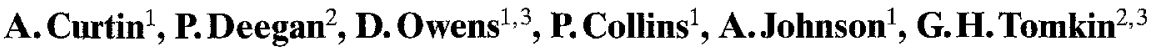 \\ ${ }^{1}$ Department of Biochemistry, Royal College of Surgeons in Ireland, Dublin, Ireland \\ ${ }^{2}$ The Adelaide Hospital, Dublin, Ireland \\ ${ }^{3}$ Department of Clinical Medicine, Trinity College, Dublin, Ireland
}

\begin{abstract}
Summary The intestine is a major site of cholesterol synthesis and produces apolipoprotein B-48, which is critical for intestinal cholesterol absorption and secretion. The purpose of this study was to examine postprandial changes in apolipoprotein B-48 in diabetes. Six non-insulin-dependent diabetic patients and six non-diabetic control subjects were given a high-fat meal $(1300 \mathrm{kcal})$ and blood samples were taken pre- and postprandially, from which the triglyceride-rich lipoprotein fraction was isolated by ultracentrifugation (density $<1.006 \mathrm{~g} / \mathrm{ml}$ ). Apolipoprotein B-48 was separated on 4-15\% gradient gels and quantified as a percentage of the fasting concentration by densitometric scanning. Total protein, triglyceride and cholesterol in the triglyceride-rich lipoprotein fraction, blood glucose, and serum insulin were also measured. Diabetic patients exhibited a postprandial triglyceride-rich apolipoprotein B-48 pro-
\end{abstract}

file significantly different from that of control subjects $(p<0.05)$. The triglyceride and total protein concentration in the triglyceride-rich lipoprotein fraction mirrored the post-prandial profile and apolipoprotein B-48 in both groups. Significantly different patterns for triglyceride $(p<0.02)$ and total protein $(p<0.05)$ following the fat-rich meal were observed in the two groups. Fasting and postprandial triglyceride-rich lipoprotein cholesterol and total apolipoprotein B were significantly higher in diabetic patients than in control subjects $(p<0.05)$. Since apolipoprotein B-48 is the structural protein of intestinally-derived lipoprotein particles, these studies suggest an abnormality in intestinal lipoprotein metabolism in diabetes. [Diabetologia (1994) 37: 1259-1264]

Key words Apolipoprotein B-48, triglyceride-rich lipoproteins, NIDDM, cholesterol, triglyceride.
Apolipoprotein B (apo B), a large hydrophobic glycoprotein, exists in the serum in two principal isoforms [1]. The hepatically-derived apolipoprotein B100 (apo B100) is present in both low density lipoprotein (LDL) and very low density lipoprotein (VLDL) and is an important ligand for the low density lipoprotein receptor [2]. Elevated levels of apo B-100

Received: 28 March 1994

and in revised form: 1 July 1994

Corresponding author: Professor G.H.Tomkin, 1 Fitzwilliam Square, Dublin 2, Ireland

Abbreviations: TRL, Triglyceride-rich lipoprotein; Apo-B48, apolipoprotein B-48; apo-B100, apolipoprotein B-100; apo E, apolipoprotein E; VLDL, very low density lipoprotein;

NIDDM, non-insulin-dependent diabetes. are a recognised risk factor for the development of coronary disease [3]. Apolipoprotein B-48 (apo B48 ) is exclusively produced in the intestine in humans and appears to be about $48 \%$ the size of apo B-100 on sodium dodecyl sulphate (SDS)-polyacrylamide gels $[1,4]$. It is produced from the apo B-100 gene by a mechanism which involves mRNA editing and contains only the amino terminal 2153 amino acids of apo B-100. The same gene expresses both apo B-48 in the intestine and apo B-100 in the liver by organ-specific alteration of the transcribed $\mathrm{mRNA}[5$, 6]. The majority of apo B-100 in human plasma is thought to be of hepatic origin, although it has been reported that the human intestine is also capable of synthesising apo B-100 [7].

Apo B-48 is necessary for the assembly of chylomicrons and therefore plays a role in the intestinal ab- 
sorption of dietary triglycerides and cholesterol. Chylomicron remnants have been implicated as being potentially atherogenic [8] and apo B-48 has been proposed as a useful indicator of intestinally-derived lipoprotein particles [1,9]. Studies have examined postprandial alterations in lipoprotein metabolism in the diabetic state $[10,11]$; however, although postprandial changes in apo B-48 have been investigated in the non-diabetic population [12], the effect of diabetes on apo B-48 is unknown. Diabetic patients have a high incidence of atherosclerosis, a disease commonly associated with dyslipidaemia. However, serum cholesterol levels are often normal suggesting that a lipoprotein factor not reflected in the lipid levels may be altered in diabetes. An increase in intestinal cholesterogenesis in diabetic animals, caused by an increase in 3-hydroxy 3-methylglutaryl coenzyme A reductase activity, has been reported $[13,14]$ but it is unknown whether intestinal cholesterol absorption and/ or synthesis is increased in human diabetes. The aim of this study was to examine the effect of non-insulin-dependent diabetes mellitus (NIDDM) on cholesterol metabolism in human subjects, using apo B-48 as a marker of intestinally-derived lipoproteins.

\section{Subjects and methods}

Subjects. The study was performed on six randomly chosen NIDDM patients attending the diabetes clinic and six non-diabetic hospital and laboratory personnel matched for fasting serum cholesterol levels, body mass index (BMI) $\mathrm{kg} / \mathrm{m}^{2}$ and sex (two females and four males in each group). The mean age of the diabetic patients was $64 \pm 4$ years and of non-diabetic subjects $53 \pm 6$ years. The mean BMI of the diabetic patients was $30 \pm 4$ and the non-diabetic subjects $29 \pm 3.5$. All subjects were normocholesterolaemic (serum cholesterol $<6.5 \mathrm{mmol} / \mathrm{l}$ ). The mean serum triglyceride of the diabetic patients was $2.4 \pm 0.5$ $\mathrm{mmol} / \mathrm{l}$ and of the non-diabetic subjects $1.3 \pm 0.2 \mathrm{mmol} / \mathrm{l}$. None of the subjects suffered from hypertension, or showed evidence of thyroid, renal or hepatic disease. Four of the diabetic patients were being treated with glibenclamide and in two, the disease was controlled with diet alone. Ethical committee approval was obtained from the hospital and all subjects gave informed consent.

Study design. Following an overnight fast, subjects were given a breakfast consisting of a glass of orange juice $(0.2 \mathrm{li}$ tre), a standard serving of cereal $(30 \mathrm{~g})$ with whole milk ( 0.15 litre), 2 fried eggs, 2 slices of fried bread $(60 \mathrm{~g}), 2$ fried tomatoes and a cup of tea ( 0.2 litre). The meal contained $1340 \mathrm{kcal}$ in which $55 \%$ of the calories were derived from fat and $25 \%$ from carbohydrates. The breakdown of the fat content was: cholesterol $0.6 \mathrm{~g}$, saturated fat $22.5 \mathrm{~g}$, polyunsaturated fat $34.1 \mathrm{~g}$ and monounsaturated fat $26.4 \mathrm{~g}$. This meal was chosen to maximise lipoprotein changes while minimising changes in metabolic control in the diabetic patients. Water, but no food, was allowed during the study period. Blood was taken from each subject prior to the test meal and at 1, 2, 4 and $6 \mathrm{~h}$ after the meal. Patients and control subjects had maintained their normal diets prior to the study.
Lipoprotein preparation and analysis. Blood was collected into heparinised tubes by venipuncture and centrifuged within $1 \mathrm{~h}$ to separate plasma and cells. After separation of plasma the following preservatives were added to prevent the degradation of apo B: PPACK (Sigma, Poole, UK) $(1 \mu \mathrm{m} / \mathrm{ml})$, phenyl methyl sulphonyl fluoride (PMSF), sodium azide $(0.02 \%)$ and ethylenediaminetetra-acetic acid (EDTA) $\left(0.1 \mathrm{~g} \cdot 1^{-1}\right)$. A triglyceride-rich lipoprotein fraction (TRL, density $<\mathrm{g} / \mathrm{mI}$ ), consisting of chylomicrons and very low density lipoprotein (VLDL), was isolated from plasma by ultracentrifugation at $40,000 \mathrm{rev} / \mathrm{min}$ for $18 \mathrm{~h}$, at $4^{\circ} \mathrm{C}$ in $6-\mathrm{ml}$ tubes using a Sorvall "Combi plus" ultracentrifugate with a fixed angle rotor (Du Pont, Steve Nage, UK). TRL samples were stored at $4{ }^{\circ} \mathrm{C}$ and used within 1 week. The volume of the TRL fraction was measured in each case but not adjusted.

Serum total cholesterol and blood glucose were measured by enzymatic colorimetric methods using kits supplied by Boehringer Mannheim GmbH (Mannheim, Germany). Serum and TRL triglycerides were measured with kits from BioMerieux (Charbonnieres les Bains, France). Blood haemoglobin $\mathrm{A} 1 \mathrm{C}(\mathrm{HbA1C})$ was determined as the percentage of total haemoglobin following ion exchange chromatography (normal value $<4.9 \%$ ). Serum total insulin was measured using a microparticle enzyme immunoassay (Abbott, Chicago, Ill., USA). Total apo B in the TRL fraction was measured by a radial-immunodiffusion using plates from Immuno $\mathrm{GMBH}$ (Heidelberg, Germany) and protein was estimated by a modification of the Lowry method [15].

Apolipoprotein $B$ analysis. TRL apolipoproteins were separated by SDS-polyacrylamide gel electrophoresis using 4$15 \%$ gradient gels supplied by Biorad (Herculas, Ca, USA). The buffer system described by Laemmli [16] was used during electrophoresis. Non-delipidated lipoprotein samples $(10 \mu \mathrm{g}$ of protein) were reduced in SDS sample buffer (3\% mercaptoethanol, $3 \%$ SDS, $0.001 \%$ bromophenol blue, $0.05 \mathrm{~mol} / 1$ Tris, $10 \%$ glycerol, $\mathrm{pH} 6.8$ ), using a $2: 1$ ratio of sample to buffer, for $4 \mathrm{~min}$ at $96^{\circ} \mathrm{C}$. Sample $(20 \mu \mathrm{l})$ was applied to the gels which were run at $200 \mathrm{~V}$ for approximately $40 \mathrm{~min}$, or until the dye front had reached the bottom of the gel. The gels were then stained for $1 \mathrm{~h}$ in $0.1 \%$ Coomassie Brilliant Blue in methanol-acetic acid-water 4.5:4.5:1 and destained in several changes of the same solvent. This gel system achieved clear reproducible separation of apo B-100 and apo B-48 bands. Baboon lymph, a rich source of apo B-48, kindly donated by Dr. Niall O'Meara (University of Chicago, Chicago, Ill., USA), was used as apolipoprotein standard. Both apo B isoforms were confirmed by Western blotting using a monoclonal antibody known to react with both apo B-100 and apo B-48 (ABB-2, Canadian Bioclinical Ltd, Scarborough, Ontario, Canada). Apolipoprotein bands on the gradient gels were scanned with a Biorad densitometer linked to a 435 personal computer with a molecular analyst software package. Apoproteins were quantified using the method described by Cohn et al. [12]. The amount of apo B-48 in each postprandial sample was calculated in relation to the concentration present in the fasting sample, according to the following formula:

$\frac{\text { D.U. T } \times \text { TRL total protein at time } \mathbf{T}(\mathrm{mg} / \mathrm{ml} \text { serum })}{\text { D.U. } \mathbf{O} \times \text { TRL total protein at time } \mathbf{O}(\mathrm{mg} / \mathrm{ml} \text { serum })} \times 100$

where D.U. = densitometric scanning units of apolipoprotein band; $\mathrm{T}=$ postprandial time point; $\mathrm{O}=$ fasting time point.

The linearity of staining was demonstrated by loading increasing concentrations $(5-25 \mu \mathrm{g})$ of TRL apolipoproteins on to gradient gels. Ten $\mu \mathrm{g}$ of TRL protein was chosen as a standard amount to load on to gels since it stained well within the 
Table 1. Clinical characteristics of the patient groups studied

\begin{tabular}{lll}
\hline & $\begin{array}{l}\text { Diabetic } \\
\text { patients }\end{array}$ & $\begin{array}{l}\text { Non-diabetic } \\
\text { subjects }\end{array}$ \\
\hline$n$ & 6 & 6 \\
$\begin{array}{l}\text { Serum cholesterol } \\
\text { (mmol/l) }\end{array}$ & $5.5 \pm 0.3$ & $6.1 \pm 0.3$ \\
$\begin{array}{l}\text { Serum triglyceride } \\
\text { (mmol/l) }\end{array}$ & $2.4 \pm 0.5$ & $1.3 \pm 0.2^{\mathrm{a}}$ \\
Mean FBG (mmol/l) & $7.6 \pm 1.2$ & $3.9 \pm 0.2^{\mathrm{b}}$ \\
Mean age (years) & $64 \pm 4$ & $53 \pm 3^{\mathrm{a}}$ \\
Mean BMI (kg/m $\left.{ }^{2}\right)$ & $30 \pm 4$ & $29 \pm 3.5$ \\
HbA1C & $6.2 \pm 0.65$ & - \\
\hline
\end{tabular}

Results as mean \pm SEM.

${ }^{\mathrm{a}} p<0.05,{ }^{\mathrm{b}} p<0.01$ with respect to diabetic subjects.

FBG, Fasting blood glucose; BMI, body mass index

linear range. The inter- and intra-assay variations were $12.3 \%$ and $6 \%$, respectively.

\section{Statistical analysis}

Statistical analysis was performed using the unpaired Student's $t$-test for comparison of fasting levels in the two groups, and by repeated measures of analysis of variance (ANOVA), to examine the postprandial profile differences between the groups, implemented on JMP (SAS C Sas Institute, Cary, N. C., USA ORP). For analysis of variance (ANOVA) data was transformed to natural log scale to correct for skewness, but the results were back-transformed for presentation purposes. Results from the model are shown as group profiles of each measured response by time. Results are expressed as the mean \pm SEM, unless otherwise stated. Inter- and intra-assay variation is expressed as $\mathrm{SD} /$ mean $\times 100$. A $p$ value of $<0.05$ was regarded as statistically significant.

\section{Results}

Baseline subject data is shown in Table 1. All subjects were normocholesterolaemic with a fasting serum cholesterol below $6.5 \mathrm{mmol} / 1$ and there was no significant difference in BMI between diabetic and non-diabetic subjects. Fasting serum triglyceride levels were higher in the patient group compared to the control $(p<0.05)$. As expected, fasting blood glucose levels were also higher in the diabetic patients $(p<0.01)$, but fasting serum insulin was similar in diabetic and non-diabetic subjects $8.9 \pm 1.2$ vs $8.1 \pm 1.5 \mathrm{mU} / \mathrm{l}$, respectively. The diabetic patients were well controlled as reflected by their HbA1c levels. The glucose and insulin profiles in the two groups following the highfat meal are shown in Fig.1. The glucose profile was found to be significantly different between the two groups over the time period studied $(p<0.001)$. Insulin changed significantly over time $(p<0.0001)$ but the difference in profile between the two groups was not significant (Fig. 1).
The postprandial changes observed in the TRL total protein and triglyceride are shown in Fig. 2. Fasting TRL triglyceride concentration was significantly higher in the diabetic patients $(0.60 \pm 0.240$ vs. $0.16 \pm 0.1 \mathrm{mg} / \mathrm{ml}$ serum, $p<0.05$ ) as was the postprandial TRL triglyceride level at all time points. The postprandial profile also differed significantly between the two groups $(p<0.01)$. The total protein concentration in the fasting samples from diabetic patients was significantly higher than control protein $(0.30 \pm 0.046$ vs. $0.04 \pm 0.01 \mathrm{mg} / \mathrm{ml}$ serum, $(p<0.01)$. The postprandial protein levels were also significantly higher in diabetic patients and the postprandial profile for TRL protein was found to be significantly different between the two groups $(p<0.05)$. Fasting TRL total apo B (apo B-100 + apo B-48) measured immunologically was significantly higher $(0.024 \pm$ 0.005 vs $0.012 \pm 0.002 \mathrm{mg} / \mathrm{ml}$ serum $p<0.05$ ) in the diabetic subjects. While the postprandial pattern of rise and fall for TRL total apo B was not statistically different between the control and diabetic subjects, the TRL apo B concentration was statistically higher in the diabetic patients both fasting and postprandially, at all time points $(p<0.01)$ (Fig. 3 ).

The postprandial profiles for apo B-48 and TRL cholesterol are shown in Fig. 4. The amount of apo B48 in each sample was calculated in relation to the concentration present in the fasting sample and therefore this profile depicts the amount of apo B-48 as a percentage change over time. The apo B-48 band was clearly resolved in all gels and was visible in all TRL fractions including the fasting sample from all subjects. Calculation of the concentration of apo B-48 in the TRL fractions involved measurement of the total TRL protein concentration and measurement of the staining intensity of the band on the polyacrylamide gel, using the formula described in the methods section. The diabetic patients exhibited a postprandial profile for apo B-48 significantly different from that of control subjects $(p<0.05)$. The pattern of postprandial change in TRL cholesterol was not significantly different between the two groups although diabetic patients had a significantly higher concentration of cholesterol in their fasting TRL $(0.12 \pm 0.045$ vs 0.03 $\pm 0.001 \mathrm{mg} / \mathrm{ml}$ serum, $p<0.05)$ and cholesterol levels were higher at all postprandial time points $(p<0.01)$.

\section{Discussion}

Postprandial lipid profiles are important since humans spend the majority of time in a non-fasting state. The intestine is responsible for a large proportion of the body's cholesterol both as a result of its function in absorption and from de novo synthesis. Apo B-48 is the structural protein for chylomicrons and thus may regulate cholesterol delivery from the intestine to the liver. 

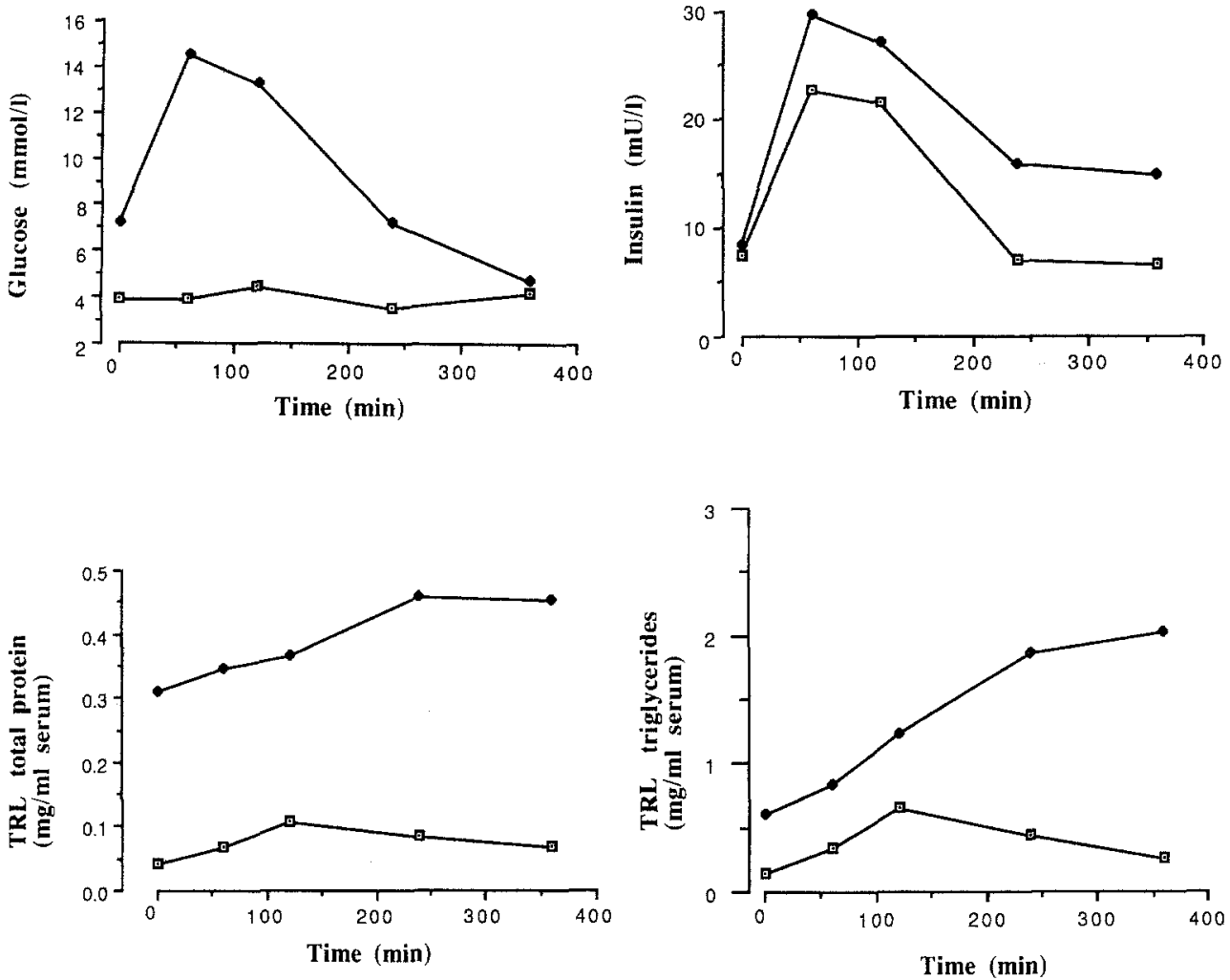

Fig. 1. Postprandial plasma insulin and glucose profiles following a high fat meal in NIDDM patients $(n=6)$ and non-diabetic subjects $\square$ $(n=6)$. There was a significant change in plasma insulin (right side) over the $6 \mathrm{~h}$ study period for both groups $(p<0.001)$ but there was no difference in the profiles between diabetic and non-diabetic subjects. The postprandial glucose profile (left side) changed significantly between the control and diabetic patients $(p=0.001)$

Fig. 2. Postprandial profiles for triglyceride and protein in the TRL lipoprotein fraction following a highfat meal in NIDDM patients $(n=6)$ and non-diabetic $\square$ subjects $(n=6)$. The TRL fraction was isolated by ultracentrifugation (density $1.006 \mathrm{~g} / \mathrm{l})$ for $22 \mathrm{~h}$ at $40,000 \mathrm{rev} / \mathrm{min}$. Both TRL triglyceride and protein were higher at each time-point in the diabetic patients and the postprandial profiles for both triglyceride and protein were significantly different between the two groups $(p<0.01$ and $p<0.05$, respectively)

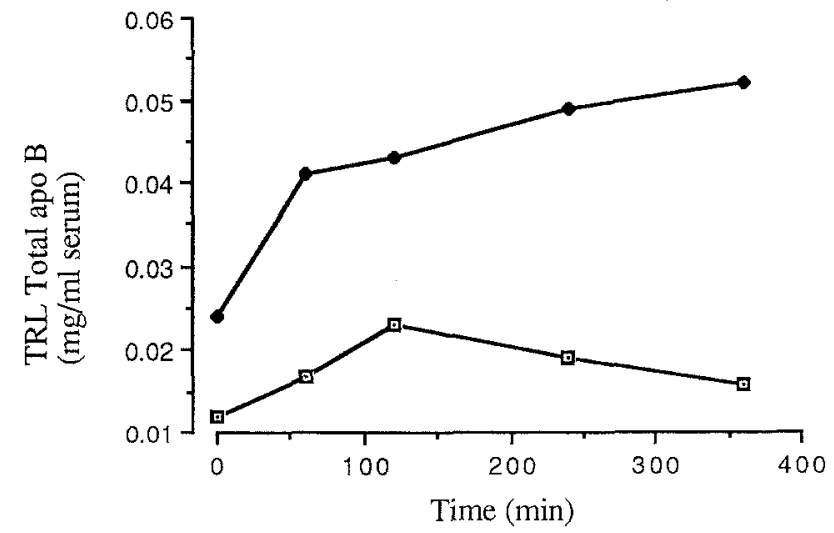

Fig.3. TRL Apo B measured by radial immunodifusion, fasting and postprandial in NIDDM $\bullet(n=6)$ and non-diabetic $\nabla$ subjects $(n=6)$. The TRL fraction was isolated by ultracentrifugation (density $1.006 \mathrm{~g} / \mathrm{l}$ ) for $22 \mathrm{~h}$ at $40,000 \mathrm{rev} / \mathrm{min}$. The level of apo B was significantly higher at fasting and at all postprandial time-points in TRL from diabetic patients $(p<0.01)$

There are considerable difficulties in measuring apo B-48 since its structure is homologous with that of apo B-100 and therefore the development of a specific antibody has been impossible. We therefore concentrated on examining the percent change from the fasting level. We used TRL for analysis of apo B-48 since the proportion of protein to triglyceride is so small in the chylomicron fraction that it is difficult to obtain reproducible results. TRL was composed of chylomicrons and VLDL, but apo B-48 is only contained in the intestinally-derived fraction. The plas- ma apolipoprotein changes in the TRL fraction of non-diabetic human subjects fed a fat-rich meal have previously been documented $[10,17]$, but to our knowledge postprandial alterations in apo B-48 in the diabetic patient have not been reported.

The diabetic subjects had a significantly increased fasting blood glucose, as would be expected, yet they had a similar fasting insulin when compared to control subjects. The insulin profile postprandially is very similar in both groups. The plateau reached in both groups at $4 \mathrm{~h}$ and the return of the blood glucose in the diabetic patients to fasting level at this time suggests that delayed gastric emptying in the diabetic patients was not a factor in the postprandial pattern of apo B-48. Although it is known that hyperglycaemia delays gastric emptying in diabetes, as does autonomic neuropathy, none of our patients showed evidence of neuropathy $[18,19]$.

The postprandial pattern exhibited by apo B- 48 following a high-fat meal is significantly different in diabetic patients when compared to the non-diabetic subjects. The diabetic subjects exhibited a postprandial profile which continued to increase up to $6 \mathrm{~h}$ (the last time point measured) whereas the control subjects show a sharper increase, reaching a peak at $2 \mathrm{~h}$ followed by a steady decline. The postprandial time period was extended in a further study when we found that apo B-48 levels in the diabetic patients were decreasing at $8 \mathrm{~h}$ and had returned to base-line by $10 \mathrm{~h}$ (data not shown). This altered pattern in the diabetic patient may reflect prolonged absorption, increased syn- 


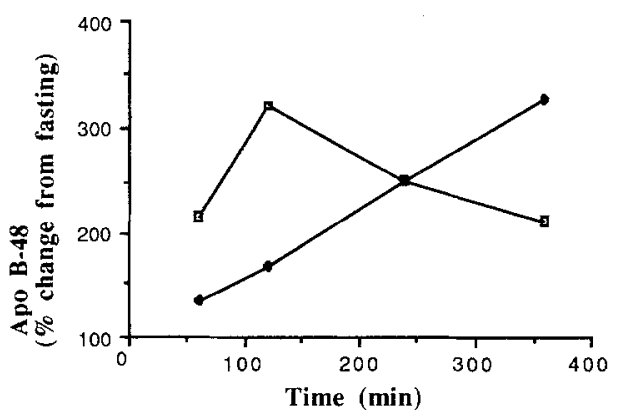

Fig.4. Post-prandial apo B-48 and cholesterol profiles in the triglyceride-rich (TRL) fraction of plasma following a high-fat meal. The TRL fraction was prepared by ultracentrifugation at a density of $1.006 \mathrm{~g} / \mathrm{l}$ for $22 \mathrm{~h}$ at $40,000 \mathrm{rev} / \mathrm{min}$. Apo B-48 was separated by SDS-polyacrylamide gel electrophoresis on 4-15\% gradient gels and quantified by scanning densitometry. The apo B-48 at each time point was expressed as \% of the fasting value. The postprandial apo B-48 profile (left side) was significantly different in NIDDM $\bullet(n=6)$ and control subjects $\square(n=6) \quad(p<0.05)$. While TRL cholesterol (right side) was significantly higher in the diabetic patients at each time point $(p<0.01)$ the postprandial change in the cholesterol profile was not different between the two groups

thesis or decreased clearance of apo B-48. Increased absorption has been shown in diabetic animals and the intestine has also been shown to increase cholesterol synthesis in diabetes in the animal model [13, $20]$. Thus, it might be expected that chylomicron cholesterol and apo B-48 would be increased in diabetic subjects postprandially. The increase in TRL cholesterol would tend to confirm the apo B-48 findings although it is possible that some of the cholesterol was derived from VLDL. A decrease in the clearance of $\mathrm{B}-48$ is to be expected since there is a delay in chylomicron clearance in both diabetic rats and diabetic human subjects [21]. The pattern of postprandial TRL triglyceride in the diabetic subjects is unlikely to be influenced by alteration in intestinal synthesis, and reflects both increased hepatic synthesis and decreased clearance due to reduced lipoprotein lipase activity.

The similarity in patterns of apo B-48, cholesterol and triglycerides suggests an important abnormality in intestinal function and clearance in diabetic subjects which might have considerable impact on the development of atherogenic LDL. It will be interesting to examine ways of improving these abnormalities with the use of diet, better postprandial diabetic control and perhaps with the use of fibrate drugs.

In conclusion, this study demonstrates that apo B-48 metabolism is significantly different in NIDDM subjects when compared to control subjects with similar serum cholesterol levels and gives further evidence of disturbed lipoprotein metabolism in NIDDM that is not reflected in levels of serum cholesterol.
Acknowledgement. The authors wish to thank the Health Research Board of Ireland for supporting this project.

\section{References}

1. Kane JP, Hardman DA, Paulus HE (1980) Heterogeneity of apolipoprotein $\mathrm{B}$ : isolation of a new species from human chylomicrons. Proc Natl Acad Sci USA 77: 24652469

2. Brown MS, Goldstein JL (1986) A receptor-mediated pathway for cholesterol homeostasis. Science 232: 34-47

3. Young SG (1990) Recent progress in understanding apolipoprotein B. Circulation 82: 1574-1594

4. Edge SB, Hoeg JM, Schneider PD, Brewer Jr HB (1985) Apolipoprotein B synthesis in humans: liver synthesizes only apolipoprotein B-100. Metabolism 34: 726-730

5. Chen SH, Habib G, Yang CY et al. (1987) Apolipoprotein $\mathrm{B}-48$ is the product of a messenger RNA with an organ-specific in-frame stop codon. Science 238: 363-366

6. Powell LM, Wallis SC, Pease RJ, Edwards YH, Knott TJ, Scott J (1987) A novel form of tissue-specific RNA processing produces apolipoprotein $\mathrm{B}-48$ in the intestine. Cell 50: $831-840$

7. Hoeg JM, Sviridov DD, Tennyson GE et al. (1990) Both apolipoproteins B-48 and B-100 are synthesized and secreted by the human intestine. J Lipid Res 31: 1761-1769

8. Zilversmit DB (1979) Atherogenesis: a postprandial phenomenon. Circulation 60: 473-485

9. Kane JP (1983) Apolipoprotein B: structural and metabolic heterogeneity. Annu Rev Physiol 45: 637-650

10. Stinson JC, Owens D, McBrinn S, Collins P, Johnson A, Tomkin GH (1993) The regulation of postprandial cellular cholesterol metabolism in type 2 diabetic and non-diabetic subjects. Diabet Med 10: 420-426

11. Garg A, Grundy SM, Unger RH (1992) Comparison of effects of high and low carbohydrate diets on plasma lipoproteins and insulin sensitivity in patients with mild NIDDM. Diabetes 41: 1278-1285

12. Cohn JS, McNamara JR, Cohn SD, Ordovas JM, Schaefer EJ (1988) Plasma apolipoprotein changes in the triglyceride-rich lipoprotein fraction of human subjects fed a fatrich meal. J Lipid Res 29: 925-936

13. O'Meara N, Devery R, Owens D, Collins P, Johnson A, Tomkin GH (1990) Cholesterol metabolism in the alloxaninduced diabetic rabbit. Diabetes 39: 626-633

14. Feingold KR, Wiley MH, MacRae G, Moser AH, Lear SR, Siperstein MD (1984) The effect of diabetes mellitus on sterol synthesis in the intact rat. Diabetes 26: 234-239

15. Markwell MAK, Haas SM, Bieber LL, Tolbert NE (1978) A modification of the Lowry procedure to simplify protein determination in membrane and lipoprotein samples. Anal Biochem 87: 206-210 
16. Laemmli UK (1970) Cleavage of structural proteins during the assembly of the head of bacteriophage T4. Nature 227: 680-685

17. Syvanne M, Hilden H, Taskinen M-R (1994) Abnormal metabolism of postprandial lipoproteins in patients with non-insulin-dependent diabetes mellitus is not related to coronary artery disease. J Lipid Res 35: 15-26

18. Horowitz M, Harding PE, Maddox AF et al (1989) Gastric and esophageal emptying in patients with type 2 (non-insulin-dependent) diabetes mellitus. Diabetologia 32: 151-159

19. Frazer RJ, Horowitz M, Maddox AF, Harding PE, Chatterton DE, Dent J (1990) Hyperglycaemia slows gastric emp- tying in type 1 (insulin-dependent) diabetes mellitus. Diabetologia 33: $675-680$

20. Young NL, Lopez DR, McNamara DJ (1988) Contributions of absorbed and dietary cholesterol and cholesterol synthesised in the small intestine in diabetic rats. Diabetes 37: 1151-1156

21. Martins IJ, Sainsbury AJ, Mamo JCL, Redgrave TC (1994) Lipid and apolipoprotein B-48 transport in mesenteric lymph and the effect of hyperplagia on the clearance of chylomicron-like emulsions in insulin-deficient rats. Diabetologia $37: 238-246$ 